\title{
Correction to: Lactococcus lactis as a safe and inexpensive source of bioactive silver composites
}

\author{
Railean-Plugaru Viorica ${ }^{1,2} \cdot$ Pomastowski Pawel $^{1,2} \cdot$ Meller Kinga $^{1,2} \cdot$ Złoch Michal $^{1,2} \cdot$ Rafinska Katarzyna $^{1,2}$. \\ Buszewski Boguslaw ${ }^{1,2}$
}

Published online: 6 April 2018

(C) Springer-Verlag GmbH Germany, part of Springer Nature 2018

\section{Correction to: Appl Microbiol Biotechnol (2017) 101:7141- 7153 \\ https://doi.org/10.1007/s00253-017-8443-x}

The authors would like to inform readers of a mistake in the acknowledgement section of the original publication of this article. The following text has been inadvertently added but has no relation to this article:

"This work was supported by Maestro-6, No. 2014/14/A/ ST4/00641 (2015-2017), and Opus 11 No. 2016/21/B/ST4/ 02130 (2016-2019) from the National Science Centre, Poland."
The correct acknowledgment is:

\section{Acknowledgements}

We would like to thank to Prof. H. Dahm and her team from Department of Microbiology, Nicolaus Copernicus University, Torun, Poland for delivering of silver bionanoparticles obtained in framework of Symfonia_I project and used for cytotoxicity comparison in this study.

The authors apologize for any inconvenience or irritation caused by this mistake.

The online version of the original article can be found at https://doi.org/ 10.1007/s00253-017-8443-x

Buszewski Boguslaw

bbusz@chem.umk.pl; bbusz@chem.uni.torun.pl

1 Department of Environmental Chemistry and Bioanalytics, Faculty of Chemistry, Nicolaus Copernicus University, Gagarina 7,

87-100 Torun, Poland

2 Interdisciplinary Centre of Modern Technology, Nicolaus Copernicus University, Wileñska 4, 87-100 Torun, Poland 